\title{
An Innovative GIS Method for Evaluating the Visibility of the Road Using the ArcMap-Tools
}

\author{
Azad Abdulhafedh \\ Department of Civil Engineering, University of Missouri, Columbia, MO, USA \\ Email: dr.azad.s.a@gmail.com
}

How to cite this paper: Abdulhafedh, A. (2019) An Innovative GIS Method for Evaluating the Visibility of the Road Using the ArcMap-Tools. Open Access Library Journal, 6: e5586

https://doi.org/10.4236/oalib.1105586

Received: July 9, 2019

Accepted: July 29, 2019

Published: August 2, 2019

Copyright (c) 2019 by author(s) and Open Access Library Inc.

This work is licensed under the Creative Commons Attribution International License (CC BY 4.0).

http://creativecommons.org/licenses/by/4.0/

\section{Open Access}

\begin{abstract}
Road visibility is critical to motorists in making decisions such as stopping, slow downing, turning, entering a traffic stream from a driveway, or merging into traffic. Adequate visibility allows motorists the time they need to avoid vehicle crashes and conflicts and will help keep roadways operating safely and smoothly. Insufficient visibility is a significant factor in roadway crashes and near collisions. This paper utilizes the ArcMap-GIS viewshed tools, and the location analysis techniques to present an evaluation of the existing visibility on portions of the interstate highway I70 in the State of Missouri compared to AASHTO requirements. The evaluation of the existing visibility is conducted on the I70 segments at Boone, Callaway, and Cooper counties. This method is a useful tool for understanding location-based risks of limited visibility on the I70 or similar highways. The GIS techniques used show that the ArcMap-GIS tools can be used effectively in determining the road visibility and locating the hazardous locations without the need for field visits. Many highways were built years before tools like geographic information systems (GIS) and other computer aided designs were available. Therefore, this method can be considered as a relevant aid for assessing geometric consistency of the I70 interstate highway and similar roads, because it identifies different segments of the road layout that offer considerably different sight distances.
\end{abstract}

\section{Subject Areas \\ Civil Engineering}

Keywords

Road Visibility, Sight Distance, ArcMap, GIS, Viewsheds, AASHTO Green Book

\section{Introduction}

According to the American Association of State Highway and Transportation 
Officials (AASHTO), the ability of a driver to see ahead on the roadway is of paramount importance for the safe and efficient operation of a vehicle. In general, sight distance refers to the driver's line of sight. Insufficient sight distance is a significant factor in roadway crashes and many other near collisions [1]. Roadway sight distance is a measure of the road visibility, which can be categorized into four types: stopping sight distance; decision sight distance; passing sight distance; and intersection sight distance. Each of these sight distances accounts for the reaction time of the driver and the subsequent time required to complete the associated stopping task. Sight distance is the length of roadway ahead that is visible to the driver [1]-[8]. Moreover, the minimum sight distance at any point on the roadway should be long enough to enable a vehicle traveling at or near the design speed to stop before reaching a stationary object in its path. Although greater length is desirable, sight distance at every point along the highway should be at least that required for a below average driver or vehicle to stop in this distance. Stopping sight distances are calculated using basic principles of physics and the relationships between various design parameters. Providing adequate sight distance on a roadway is one of the central tasks of the designer. Adequate sight distance provides motorists the opportunity to avoid obstacles on the roadway, to merge smoothly with other traffic, and to traverse intersections safely. Ramp, interchange, and intersection designs are typically completed in tightly constrained spaces with many structural, earthwork, and roadway elements present that may obstruct sight distance. These elements are not easily moved; if consideration to sight distance constraints is not given early in the design process, designs may be compromised and may reduce the level of safety on the completed roadway. Therefore, sight distance criteria must be presented in a clear, comprehensive, and unambiguous manner to facilitate the completion of satisfactory roadway design [2] [7]-[17].

For instance, the minimum length of the highway vertical curves is controlled by the required stopping sight distance, driver eye height, and object height. This required length of curve is such that, at a minimum, the stopping sight distance is available at all points along the curve. Sight distance criteria have impact on virtually all elements of highway design and many elements of the traffic operation, and control. The roadway geometric design features, presence of obstacles to sight at the roadsides and the pavement surface condition are fixed by sight distance requirements. The nature of traffic controls, their placement and their effects on traffic stream conditions, such as traffic queues, must take account of sight distance requirements. Adequate stopping sight distance must be provided on $100 \%$ of the street and highway system so a driver with the standard eye height of $1080 \mathrm{~mm}$ may see an object of $600 \mathrm{~mm}$ with sufficient time to stop safely [1] [2] [13] [14] [15].

An essential function in GIS systems is the visibility analysis that provides the ability to analyze the visible areas or judges the intervisibility between two points. ArcGIS allows to determine visibility on a surface from point to point along a given line of sight or across the entire surface in a viewshed that identi- 
fies the cells in an input raster that can be seen from one or more observation points or lines. Each cell in the output raster receives a value that indicates how many observation points can see the location [3] [14] [15] [16] [17] [18].

This paper utilizes the GIS tools, the Viewshed applications, and the location science and analysis techniques to present an evaluation of the existing stopping sight distances on portions of the interstate highway I70 in the State of Missouri. The evaluation of the sight distances is conducted on the I70 segments at Boone, Callaway, and Cooper counties. A design speed of $70 \mathrm{mph}(110 \mathrm{~km} / \mathrm{h})$ was selected for the purpose of evaluation, and a corresponding standard AASHTO stopping sight distance of $730 \mathrm{ft}(220 \mathrm{~m})$ was compared against the existing sight distances at these portions of I70.

Many highways were built years before tools like geographic information systems (GIS) and other computer aided design were available. Therefore, this method can be considered as a relevant aid for assessing geometric consistency of the I70 interstate highway and/or similar roads, because it identifies different segments of the road layout that offer considerably different sight distances.

A stopping sight distance profile presented in this paper can also be a useful tool for understanding location-based risk of limited stopping sight distance. The profile shows the spots of insufficient stopping sight distance along the roadway, thereby illustrating the sight distance restrictions and where they occur. This information can help designers understand the severity of a sight distance restriction, how the restriction may interact with other roadway conditions or features, and how/where to implement mitigation strategies [9] [12] [15] [18].

\section{Data}

The data used are obtained from the Missouri Spatial Data Information Service (MSDIS) website http://msdis.missouri.edu/. Six quadrangles are used for the analysis, as shown in Table 1.

\section{Methodology}

ArcGIS Desktop (ArcMap version 10.6.1) is used in the analysis. The data is uploaded, and the main goal was to create Viewsheds, generate the I70 profiles and cartographic maps, and identify the points that do not meet the ASSHTO sight distance requirements. The profiles and the classified sections of the I70 were thoroughly inspected, and the existing sight distances of all points on the highway interstate I-70 within Callaway, Boone, and Cooper counties were compared against the recommended AASHTO stopping sight distance of $730 \mathrm{ft}$ (220 $\mathrm{m})$ that corresponds to the design speed of $70 \mathrm{mph}(110 \mathrm{~km} / \mathrm{h})$ of the I70 interstate highway.

The following steps are conducted throughout the analysis:

- Importing the downloaded E00 interchange files in GIS

- Densifying the I70 raster

- Converting the Vertices of I70 Features to Points 
Table 1. Data files used in the analysis.

\begin{tabular}{ccc}
\hline Quadrangle Code & Type of the file & County \\
\hline g38092h2.e00.gz & E00 & Boone-Callaway \\
g38092h3.e00.gz & E00 & Boone \\
g38092h4.e00.gz & E00 & Boone \\
g38092h5.e00.gz & E00 & Boone-Cooper \\
g38092h10.e00.gz & E00 & Callaway \\
g38091h8.e00.gz & E00 & Callaway \\
\hline
\end{tabular}

- Adding new parameters to the attribute table of the point's raster that control the visibility analysis in the viewsheds. These parameters are (OFFSET A = $1.08 \mathrm{~m}$ presenting the height of the driver's eye recommended by AASHTO, OFFSET $\mathrm{B}=0.6 \mathrm{~m}$ presenting the height of object above the road surface recommended by AASHTO, AZIMUTH $1=0$, AZIMUTH $2=180$ degrees, Vertical Angle $1=+90$ degrees, Vertical Angle $2=-90$ degrees, RADIUS $1=$ 0 , RADIUS $2=560 \mathrm{~m}$ presenting the radius of curvature recommended by AASHTO).

- Creating viewsheds for all points of the $\mathrm{I} 70$ raster

- Buffering the DEMs by a distance of $200 \mathrm{~m}$

- Clipping the DEMs by the road buffers

- Connecting the buffered-clipped DEMs of all segments together by ArcMap Mosaic tools

- Generating the I70 profiles, and classified maps from the viewshed's

- Identifying the IDs, and the geographic coordinates of all the points along the highway that did not meet the AASHTO recommended sight distance of 220 $\mathrm{m}$

The main steps of the procedure are detailed below:

1) Import the $\mathrm{E} 00$ interchange files:

The E00 interchange files that are downloaded from the MSDIS website, were imported as follows:

(Arc Toolbox $\geq$ Conversion Tools $\geq$ To Coverage $\geq$ Import from E00).

2) Densify the $I-70$ rasters':

Steps used are:

(Arc Toolbox $\geq$ Editing Tools $\geq$ Densify).

The Densification method was chosen to be (Distance), and the value of the Distance entered was (220 meter), which is the AASHTO recommended sight distance that corresponds to the design speed (70 mph).

\section{3) Feature Vertices to Points:}

The feature vertices of the I-70 are converted to points using,

(Arc Toolbox $\geq$ Data Management Tools $\geq$ Features $\geq$ Feature Vertices to Points).

4) Add new fields and parameters to the attribute table of the new Vertices to Points layer: 
In order to control the visibility area, and creating the viewsheds accordingly, the following fields and parameters were added to the attribute table of the Vertices to Points layer:

- OFFSET A_1 = 1.08 meter, which presents the height of the driver's eye above the road surface that is recommended by AASHTO Green Book, 2011.

- OFFSETB $=0.6$ meter, which presents the height of the visible object on the road surface recommended by AASHTO Green Book, 2011.

- AZIMUTH_1 = 0 degree, which defines the start angle of the scan range

- AZIMUTH $2=180$ degree, which defines the end angle of the scan range

- Vertical Angle 1 (VERT 1) = 90 degree, which defines the upper vertical angle limit of the scan

- Vertical Angle 2 (VERT 2) $=-90$ degree, which defines the lower vertical angle limit of the scan

- RADIUS $1=0$ meter, which defines the start distance from which visibility is determined

- RADIUS $2=560$ meter, which defines the end distance from which visibility is determined, this value was chosen because it presents the recommended radius of curvature by AASHTO that corresponds to the design speed of (70 $\mathrm{mph}$ ).

\section{5) Creating Viewsheds}

Viewsheds are created for all points at once, using the following steps:

(Arc Toolbox $\geq 3$ D Analysis Tools $\geq$ Visibility $\geq$ Viewsheds),

The input raster: the quadrangle raster file,

The input points feature: The Vertices To Points,

The output Raster: the Viewshed that corresponds to the quadrangle used, The $\mathrm{Z}$ factor was used as 1 ,

The earth curvature corrections is checked to be applied, and

The Refractivity Coefficient is taken as the default value of 0.13

\section{6) Modify the DEM by Buffering the Highway:}

Each quadrangle raster layer of the I-70 interstate highway is buffered using an adequate distance around the I-70 for the purpose of evaluating the sight distances along the highway, and a distance of 200 meter is chosen as the buffering distance, as follows: (Customize $\geq$ Toolbar $\geq$ Editor $\geq$ Buffer).

7) Clipping the DEMs by the road buffer:

Each buffered quadrangle is clipped by the road buffer, as follows:

(Customize $\geq$ Toolbar $\geq$ Editor $\geq$ Clip).

8) Mosaic the modified DEMs of all quadrangles together:

The modified DEMs from the different quadrangles are connected together using the Mosaic command, as follows:

(Arc Toolbox $\geq$ Data Management Tools $\geq$ Raster $\geq$ Raster Dataset $\geq$ Mosaic to New Raster), The input raster's used were all created viewsheds of all the quadrangles.

The number of bands is $=1$,

The mosaic operator is the default (LAST), 
The mosaic Mode is the default (FIRST).

9) Identifying the locations that did not meet the recommended AASHTO Stopping Sight Distance of $220 \mathrm{~m}$ :

The profile of each quadrangle's viewshed is inspected along the I-70 interstate highways to highlight the locations or spots that did not meet the recommended AASHTO Stopping Sight Distance of $(220 \mathrm{~m})$. The points that fell short of the AASHTO standard sight distance were identified by inspection, and their IDs, and their geographic coordinates were determined by right-clicking on the location and using the "identify tools" that give the required information on that specific point or location.

\section{Results and Findings}

The map of the I70 profile at each quadrangle is generated from its corresponding viewshed and is classified into 5 classes to further show the locations that are visible and non-visible on the map. Since the points are separated originally by a distance of $220 \mathrm{~m}$ when converted from vertices to points, then obviously the non-visible locations are those points that did not meet the AASHTO recommended sight distance of $220 \mathrm{~m}$ along the highway profile. A thorough inspection is conducted for the whole profile at each quadrangle, and the non-visible points are identified in term of their IDs and geographic coordinates and tabulated to present the locations of the insufficient sight distances along the I70 highway. The Object IDs, the Pixel Values, and the counts for each viewshed can be obtained from the attribute table of the viewshed and were tabulated for each viewshed/quadrangle. The overall profile of the I70 highway at each quadrangle, and the classified sections are shown below with the tables that contain the points that did not meet the AASHTO sight distance.

\section{1. $1^{\text {st }}$ Quadrangle}

The I-70 Profile at the 1st quadrangle in Callaway County is shown in Figure 1 below:

The classified section of the I-70 Interstate Highway at the $1^{\text {st }}$ quadrangle in the Callaway County is shown in Figure 2 and Figure 3.

For the $1^{\text {st }}$ quadrangle (g38091h8, located in Callaway County), the Object IDs, the Pixel Values, and the counts are found from the attribute table of the viewshed, and as shown in Table 2.

The locations that did not meet the AASHTO standard stopping sight distance of $220 \mathrm{~m}$ at the $1^{\text {st }}$ quadrangle, are shown in Table 3.

\section{2. $2^{\text {nd }}$ Quadrangle}

The I-70 Profile at the $2^{\text {nd }}$ quadrangle in Callaway County is shown in Figure 4.

The classified section of the I-70 Interstate Highway at the $2^{\text {nd }}$ quadrangle in the Callaway County is shown in Figure 5 and Figure 6. 




Figure 1. The I-70 Profile (Visible/Not Visible) at the 1st quadrangle in Callaway County.

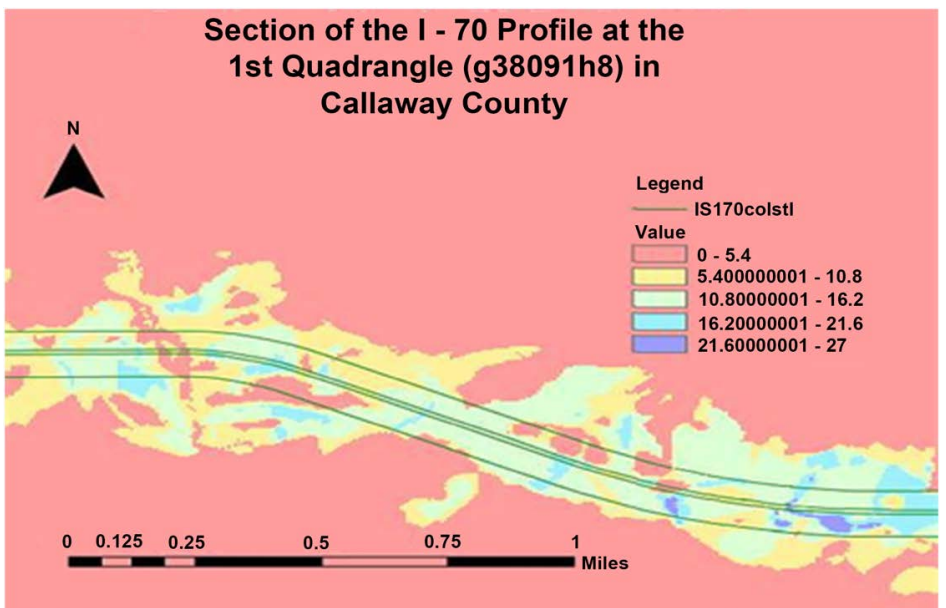

Figure 2. The I-70 Profile (Visible/Not Visible) at the 1st quadrangle in Callaway County.

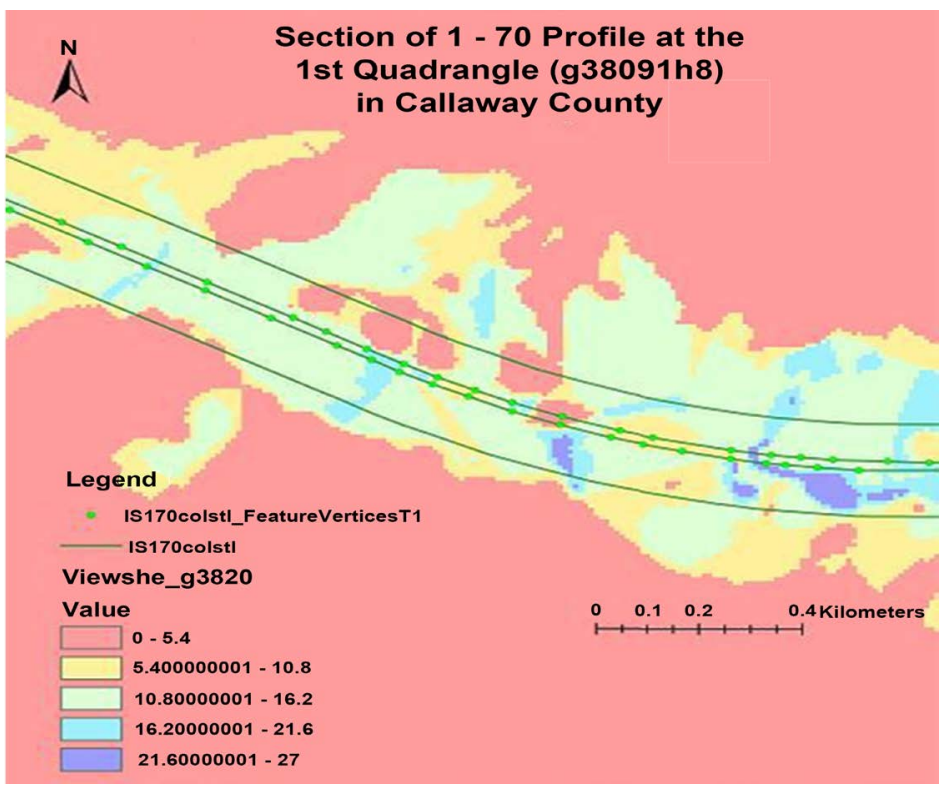

Figure 3. The classified I-70 Profile (second image) at the 1st quadrangle in Callaway County. 


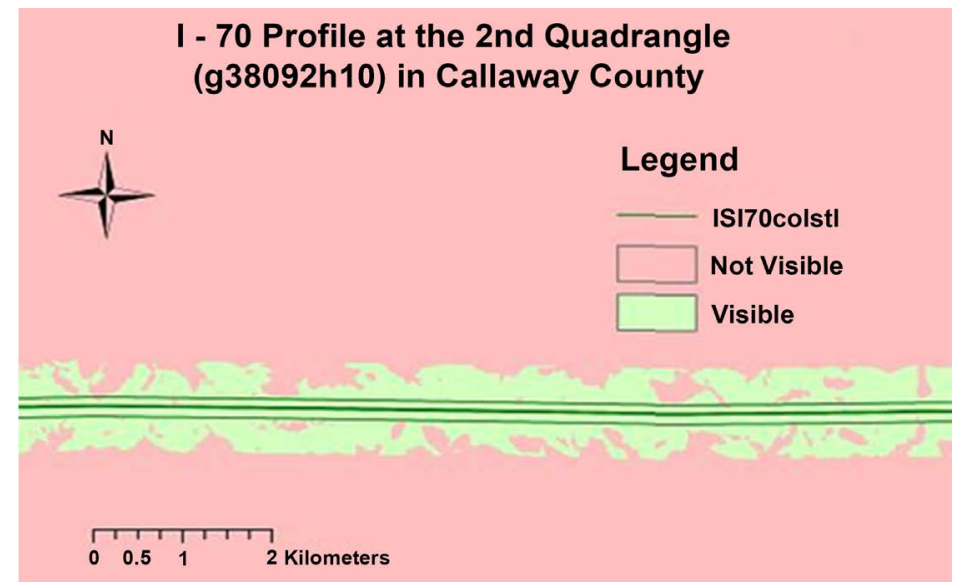

Figure 4. The I-70 Profile (Visible/Not Visible) at the $2^{\text {nd }}$ quadrangle in Callaway County.

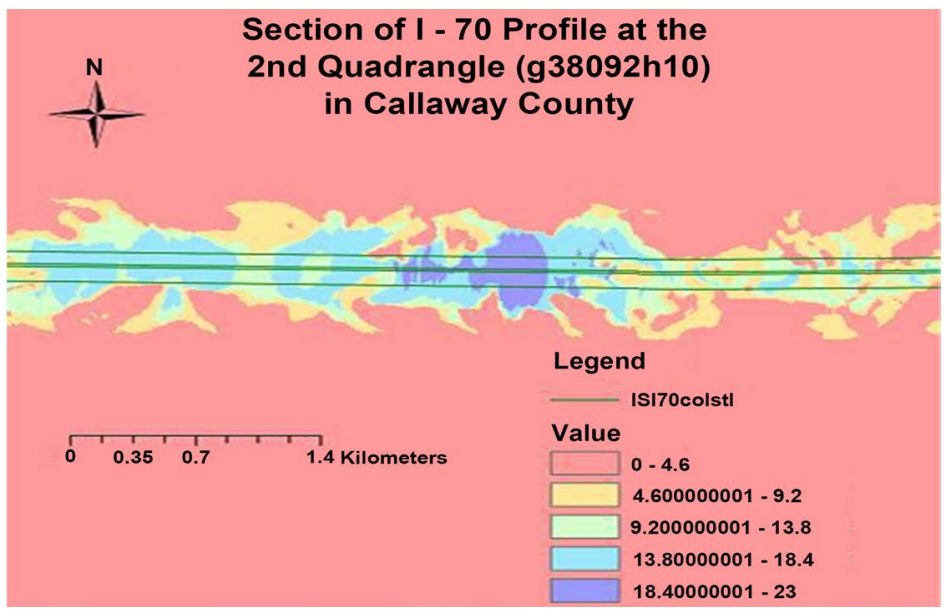

Figure 5. The $\mathrm{I}-70$ classified Profile at the $2^{\text {nd }}$ quadrangle in Callaway County.

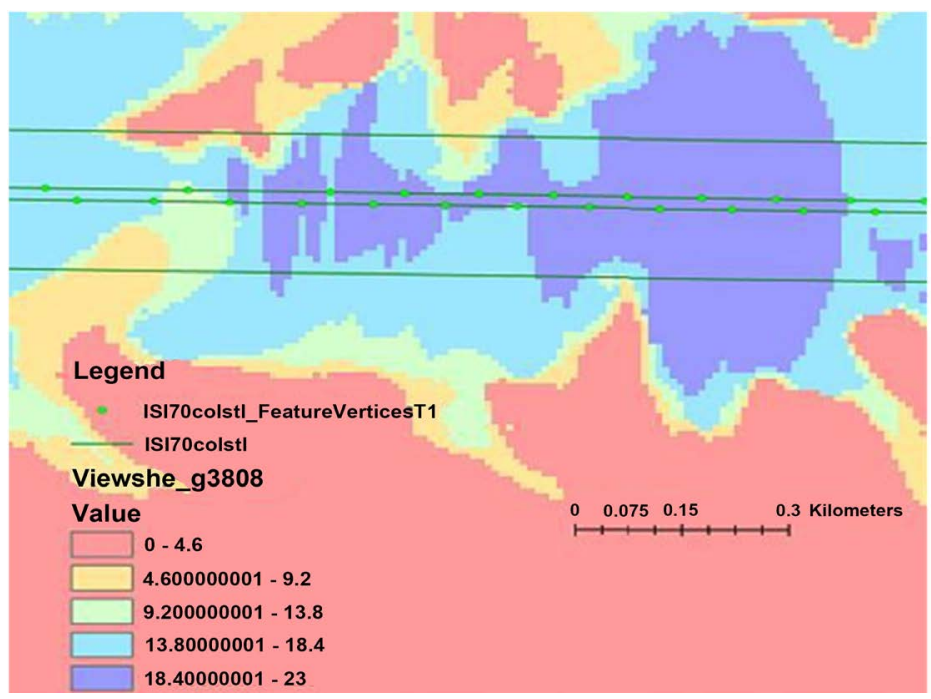

Figure 6. The I-70 classified Profile (second image) at the $2^{\text {nd }}$ quadrangle in Callaway County. 
Table 2. Object IDs and counts in Callaway County.

\begin{tabular}{cccccc}
\hline Object ID & Pixel Value & Count & Object ID & Pixel Value & Count \\
\hline 1 & 0 & $1,454,397$ & 15 & 14 & 2575 \\
2 & 1 & 5296 & 16 & 15 & 1467 \\
3 & 2 & 7557 & 17 & 16 & 1514 \\
4 & 3 & 6687 & 18 & 17 & 793 \\
5 & 4 & 10,249 & 19 & 18 & 996 \\
6 & 5 & 7817 & 20 & 19 & 533 \\
7 & 6 & 8953 & 21 & 20 & 439 \\
8 & 7 & 6626 & 22 & 21 & 280 \\
9 & 8 & 7479 & 23 & 22 & 287 \\
10 & 9 & 5466 & 24 & 23 & 269 \\
11 & 10 & 6326 & 25 & 24 & 224 \\
12 & 11 & 5372 & 26 & 25 & 83 \\
13 & 12 & 5372 & 27 & 26 & 70 \\
14 & 13 & 2887 & 28 & 27 & 2 \\
\hline
\end{tabular}

Table 3. Objects and locations of insufficient sight distance at 1st quadrangle.

\begin{tabular}{|c|c|c|c|}
\hline Object ID & Pixel Value & \multicolumn{2}{|c|}{$\begin{array}{l}\text { Geographic Coordinates of } \\
\text { the Location }(\mathrm{m})\end{array}$} \\
\hline \multicolumn{4}{|c|}{ E-W Direction } \\
\hline 5 & 4 & $594,070.439$ & $4,311,304.627$ \\
\hline 10 & 9 & $592,567.603$ & $4,311,304.627$ \\
\hline 9 & 8 & $590,605.714$ & $4,311,563.919$ \\
\hline 7 & 6 & $587,562.999$ & $4,312,132.774$ \\
\hline \multicolumn{4}{|c|}{ W-E Direction } \\
\hline 10 & 9 & $588,541.959$ & $4,311,735.898$ \\
\hline 6 & 5 & $589,507.691$ & $4,311,735.898$ \\
\hline 3 & 2 & $592,748.843$ & $4,310,876.001$ \\
\hline
\end{tabular}

For the $2^{\text {nd }}$ quadrangle (g38092h10, located in Callaway County), the Object IDs, the Pixel Values, and the counts are found from the attribute table of its viewshed, and as shown in Table 4.

The locations that did not meet the AASHTO standard stopping sight distance of $220 \mathrm{~m}$ at the $2^{\text {nd }}$ quadrangle, are shown in Table 5 .

\subsection{3 ${ }^{\text {rd }}$ Quadrangle}

The I-70 Profile at the $3^{\text {rd }}$ quadrangle in Boone-Callaway Counties is shown in Figure 7.

The classified section of the $\mathrm{I}-70$ Interstate Highway at the $3^{\text {rd }}$ quadrangle in the Boone-Callaway Counties is shown in Figure 8 and Figure 9. 
Table 4. Object IDs and Counts at the 2nd quadrangle.

\begin{tabular}{cccccc}
\hline Object ID & Pixel Value & Count & Object ID & Pixel Value & Count \\
\hline 1 & 0 & 1446,655 & 13 & 12 & 3908 \\
2 & 1 & 5874 & 14 & 13 & 3188 \\
3 & 2 & 9128 & 15 & 14 & 3595 \\
4 & 3 & 7247 & 16 & 15 & 3306 \\
5 & 4 & 9042 & 17 & 16 & 2667 \\
6 & 5 & 6795 & 18 & 17 & 1500 \\
7 & 6 & 8777 & 19 & 18 & 1400 \\
8 & 7 & 6038 & 20 & 19 & 1194 \\
9 & 8 & 6728 & 21 & 20 & 573 \\
10 & 9 & 5223 & 22 & 21 & 664 \\
11 & 10 & 5626 & 23 & 22 & 177 \\
12 & 11 & 4281 & 24 & 23 & 16 \\
\hline
\end{tabular}

Table 5. Locations with insufficient sight distance at the 2nd quadrangle.

\begin{tabular}{|c|c|c|c|}
\hline Object ID & Pixel Value & \multicolumn{2}{|c|}{ Geographic Coordinates of the Location (m) } \\
\hline \multicolumn{4}{|c|}{ E-W Direction } \\
\hline 5 & 4 & $585,828.440$ & $4,312,081.055$ \\
\hline 7 & 6 & $584,124.520$ & $4,312,081.055$ \\
\hline 1 & 0 & $578,716.426$ & $4,312,144.555$ \\
\hline 1 & 0 & $578,769.343$ & $4,312,144.555$ \\
\hline 10 & 9 & $578,155.508$ & $4,312,165.722$ \\
\hline 7 & 6 & $577,605.174$ & $4,312,155.139$ \\
\hline 3 & 2 & $577,404.090$ & $4,312,176.305$ \\
\hline 2 & 1 & $576,451.588$ & $4,312,218.639$ \\
\hline 4 & 3 & $576,176.421$ & $4,312,218.726$ \\
\hline \multicolumn{4}{|c|}{ W-E Direction } \\
\hline 6 & 5 & $576,620.922$ & $4,311,901.138$ \\
\hline 7 & 6 & $576,747.922$ & $4,311,954.055$ \\
\hline 7 & 6 & $576,949.006$ & $4,311,774.138$ \\
\hline 5 & 4 & $577,531.090$ & $4,311,784.721$ \\
\hline 4 & 3 & $578,536.509$ & $4,311,795.305$ \\
\hline 3 & 2 & $579,086.843$ & $4,311,763.555$ \\
\hline
\end{tabular}

For the $3^{\text {rd }}$ quadrangle (g38092h2, located between Boone-Callaway Counties), the Object IDs, the Pixel Values, and the counts were found from the attribute table of its viewshed, and as shown in Table 6. 


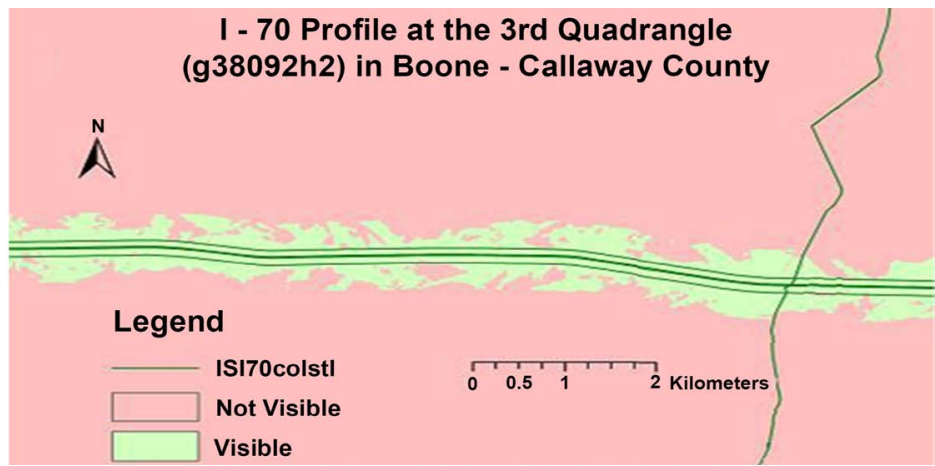

Figure 7. The I-70 Profile (Visible/Not Visible) at the $3^{\text {rd }}$ quadrangle in Boone-Callaway Counties.

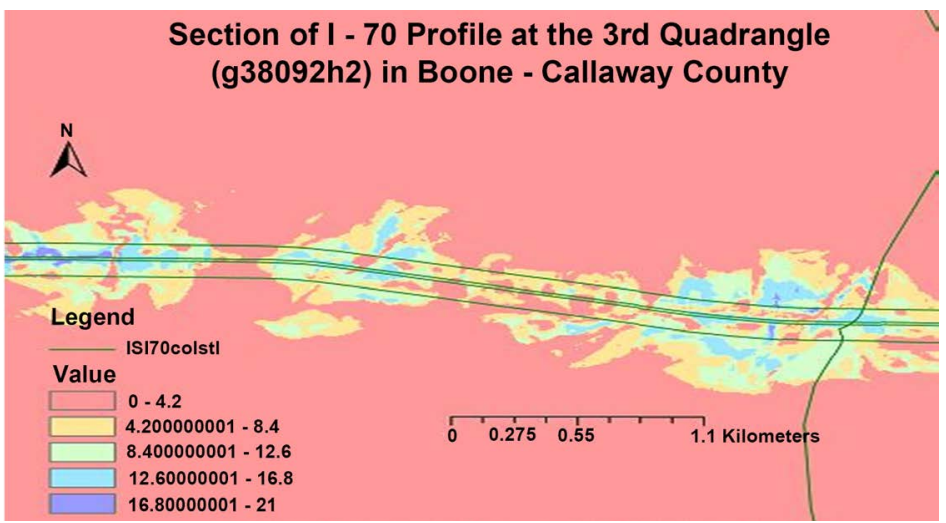

Figure 8. The I-70 classified Profile at the $3^{\text {rd }}$ quadrangle in Boone-Callaway Counties.



Figure 9. The I-70 classified Profile (second image) at the $3^{\text {rd }}$ quadrangle in Boone-Callaway Counties. 
Table 6. Object IDs and Counts at the 3rd quadrangle.

\begin{tabular}{cccccc}
\hline Object ID & Pixel Value & Count & Object ID & Pixel Value & Count \\
\hline 1 & 0 & $1,454,209$ & 12 & 11 & 3765 \\
2 & 1 & 6567 & 13 & 12 & 3177 \\
3 & 2 & 9834 & 14 & 13 & 2272 \\
4 & 3 & 7810 & 15 & 14 & 1999 \\
5 & 4 & 10,174 & 16 & 15 & 1265 \\
6 & 5 & 7095 & 17 & 16 & 834 \\
7 & 6 & 7310 & 18 & 17 & 274 \\
8 & 7 & 6295 & 19 & 18 & 146 \\
9 & 8 & 7310 & 20 & 19 & 99 \\
10 & 9 & 5550 & 21 & 20 & 55 \\
11 & 10 & 5036 & 22 & 21 & 24 \\
\hline
\end{tabular}

The locations that did not meet the AASHTO standard stopping sight distance of $220 \mathrm{~m}$ at the $3^{\text {rd }}$ quadrangle, are shown in Table 7.

\section{4. $4^{\text {th }}$ Quadrangle}

The I-70 Profile at the 4th quadrangle in Boone County is shown in Figure 10.

The classified section of the I-70 Interstate Highway at the 4th quadrangle in the Boone County is shown in Figure 11 and Figure 12.

For the 4th quadrangle (g38092h3, located in Boone County), the Object IDs, the Pixel Values, and the counts were found from the attribute table of its viewshed, and are shown in Table 8.

The locations that did not meet the AASHTO standard stopping sight distance of $220 \mathrm{~m}$ at the $4^{\text {th }}$ quadrangle are shown in Table 9.

\section{5. $5^{\text {th }}$ Quadrangle}

The I-70 Profile at the 5th quadrangle in Boone County is shown in Figure 13.

The classified section of the I-70 Interstate Highway at the 5th quadrangle in the Boone County is shown in Figure 14 and Figure 15.

For the 5th quadrangle (g38092h4, located in Boone County), the Object IDs, the Pixel Values, and the counts were found from the attribute table of its viewshed are shown in Table 10.

The locations that did not meet the AASHTO standard stopping sight distance of $220 \mathrm{~m}$ at the $5^{\text {th }}$ quadrangle, are shown in Table 11.

\section{6. $6^{\text {th }}$ Quadrangle}

The I-70 Profile at the 6th quadrangle in Boone-Cooper Counties is shown in Figure 16. 
Table 7. Locations with insufficient sight distance at the 3rd quadrangle.

\begin{tabular}{|c|c|c|c|}
\hline Object ID & Pixel Value & \multicolumn{2}{|c|}{ Geographic Coordinates of the Location (m) } \\
\hline \multicolumn{4}{|c|}{ E-W Direction } \\
\hline 3 & 2 & $574,534.162$ & $4,312,171.232$ \\
\hline 13 & 12 & $573,391.160$ & $4,312,255.898$ \\
\hline 3 & 2 & $573,010.159$ & $4,312,308.815$ \\
\hline 3 & 2 & $573,010.159$ & $4,312,298.232$ \\
\hline 5 & 4 & $571,327.406$ & $4,312,668.649$ \\
\hline 11 & 10 & $570,237.320$ & $4,312,689.816$ \\
\hline 8 & 7 & $568,046.566$ & $4,312,668.649$ \\
\hline 5 & 4 & $565,675.895$ & $4,312,763.899$ \\
\hline 4 & 3 & $565,294.894$ & $4,312,795.650$ \\
\hline \multicolumn{4}{|c|}{ W-E Direction } \\
\hline 5 & 4 & $565,517.144$ & $4,312,393.482$ \\
\hline 14 & 13 & $566,744.813$ & $4,312,435.816$ \\
\hline 5 & 4 & $567,591.482$ & $4,312,351.149$ \\
\hline 6 & 5 & $568,575.734$ & $4,312,277.065$ \\
\hline 5 & 4 & $569,507.069$ & $4,312,298.232$ \\
\hline 1 & 0 & $569,877.486$ & $4,312,287.649$ \\
\hline 3 & 2 & $571,253.322$ & $4,312,277.065$ \\
\hline 1 & 0 & $572,131.741$ & $4,312,128.898$ \\
\hline 5 & 4 & $574,449.496$ & $4,311,811.398$ \\
\hline 2 & 1 & $575,359.664$ & $4,311,758.481$ \\
\hline
\end{tabular}

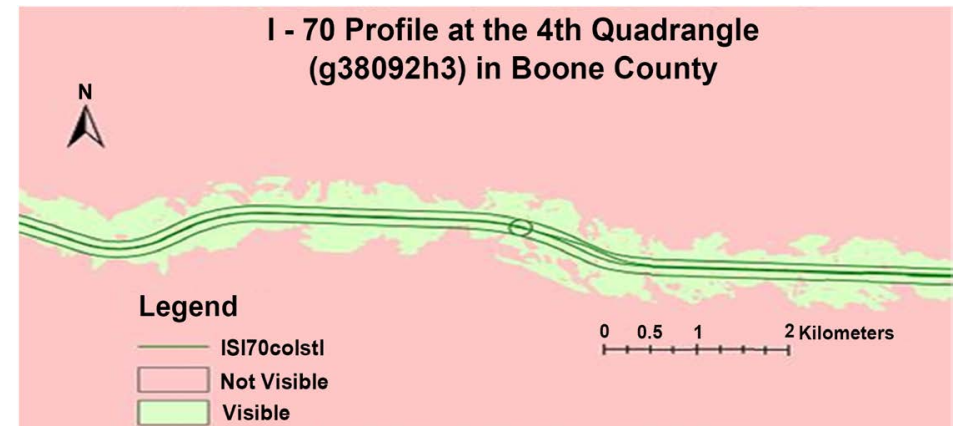

Figure 10. The I-70 Profile (Visible/Not Visible) at the $4^{\text {th }}$ quadrangle in Boone County.

The classified section of the I-70 Interstate Highway at the 6th quadrangle in the Boone-Cooper Counties is shown in Figure 17-19.

For the 6th quadrangle (g38092h5, located in Boone-Cooper Counties), the Object IDs, the Pixel Values, and the counts were found from the attribute table of its viewshed, and are shown in Table 12 . 




Figure 11. The I-70 classified Profile at the $4^{\text {th }}$ quadrangle in Boone County.



Figure 12. The I-70 classified Profile (second image) at the $4^{\text {th }}$ quadrangle in Boone County.

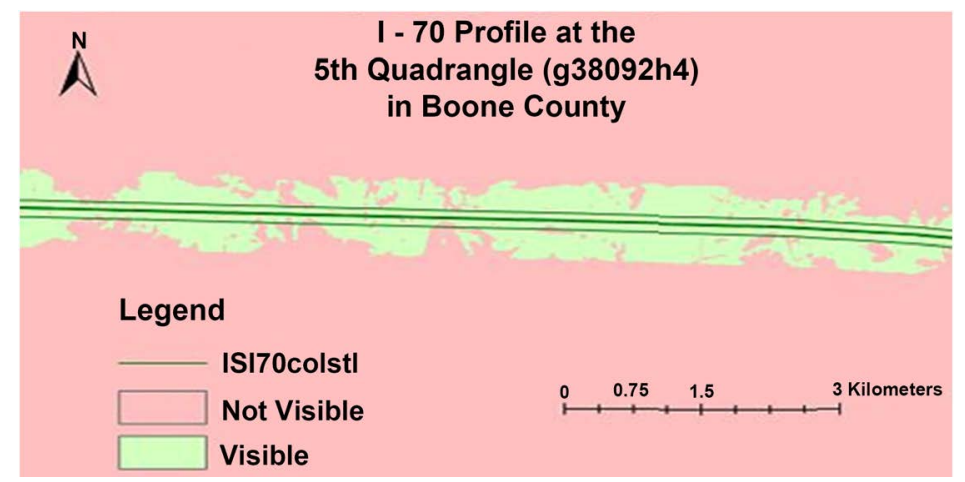

Figure 13. The I-70 Profile (Visible/Not Visible) at the $4^{\text {th }}$ quadrangle in Boone County. 


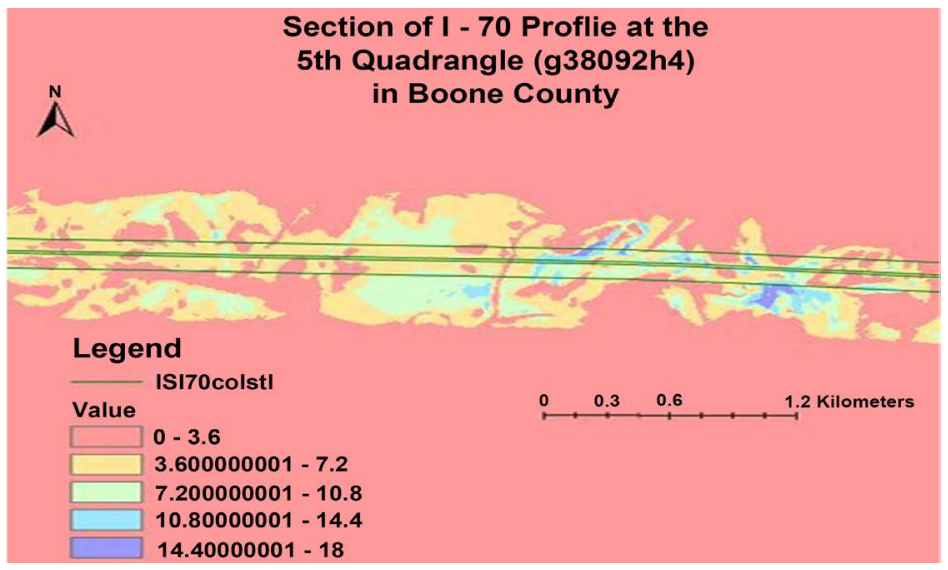

Figure 14. The I-70 classified Profileat the $5^{\text {th }}$ quadrangle in Boone County.

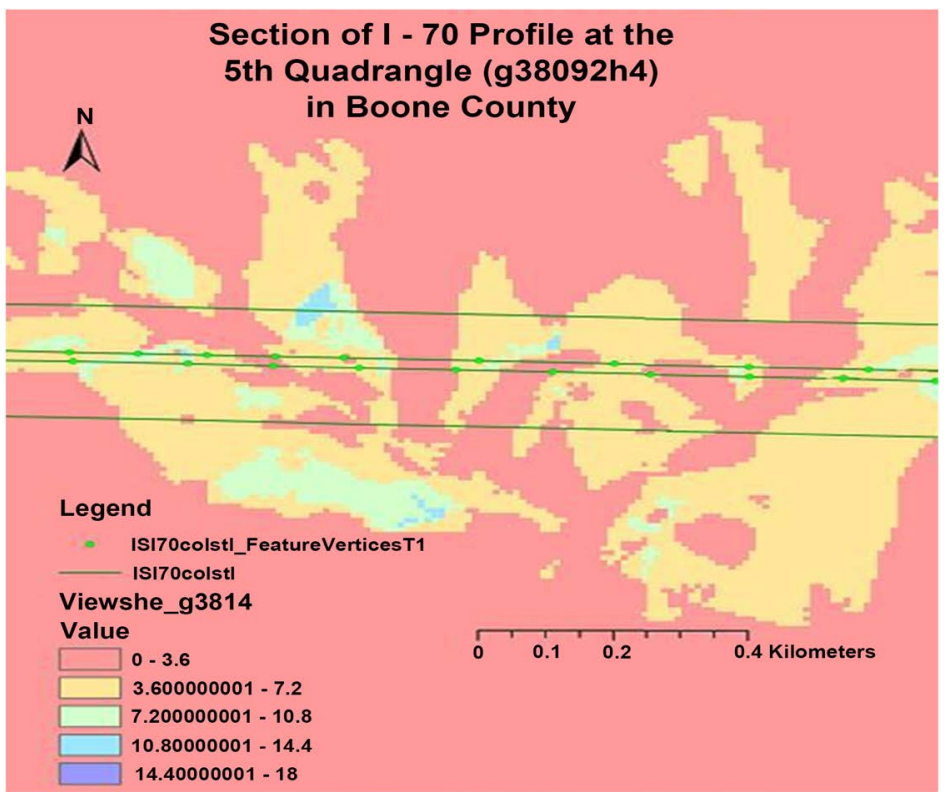

Figure 15. The I-70 classified Profile (second image) at the $5^{\text {th }}$ quadrangle in Boone County.

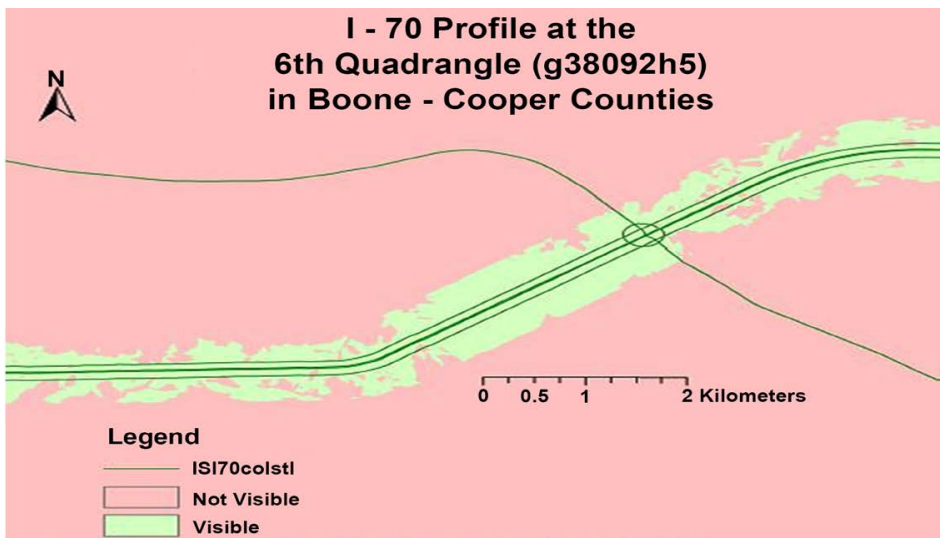

Figure 16. The I-70 Profile (Visible/Not Visible) at the $6^{\text {th }}$ quadrangle in Boone-Cooper Counties. 
Table 8. Object IDs and Counts at the 4th quadrangle.

\begin{tabular}{|c|c|c|c|c|c|}
\hline Object ID & Pixel Value & Count & Object ID & Pixel Value & Count \\
\hline 1 & 0 & $1,455,300$ & 23 & 22 & 747 \\
\hline 2 & 1 & 5453 & 24 & 23 & 397 \\
\hline 3 & 2 & 8129 & 25 & 24 & 249 \\
\hline 4 & 3 & 7526 & 26 & 25 & 224 \\
\hline 5 & 4 & 7179 & 27 & 26 & 171 \\
\hline 6 & 5 & 7177 & 28 & 27 & 202 \\
\hline 7 & 6 & 5648 & 29 & 28 & 117 \\
\hline 8 & 7 & 5522 & 30 & 29 & 113 \\
\hline 9 & 8 & 4985 & 31 & 30 & 97 \\
\hline 10 & 9 & 4005 & 32 & 31 & 45 \\
\hline 11 & 10 & 3136 & 33 & 32 & 52 \\
\hline 12 & 11 & 3430 & 34 & 33 & 32 \\
\hline 13 & 12 & 2625 & 35 & 34 & 29 \\
\hline 14 & 13 & 2162 & 36 & 35 & 25 \\
\hline 15 & 14 & 1667 & 37 & 36 & 15 \\
\hline 16 & 15 & 1480 & 38 & 37 & 7 \\
\hline 17 & 16 & 1574 & 39 & 38 & 9 \\
\hline 18 & 17 & 1482 & 40 & 39 & 8 \\
\hline 19 & 18 & 1573 & 41 & 40 & 18 \\
\hline 20 & 19 & 1465 & 42 & 41 & 24 \\
\hline 21 & 20 & 1312 & 43 & 42 & 33 \\
\hline 22 & 21 & 650 & 44 & 43 & 8 \\
\hline
\end{tabular}

Table 9. Locations with insufficient sight distance at the 4th quadrangle.

\begin{tabular}{c|ccc}
\hline Object ID & Pixel Value & \multicolumn{2}{c}{ Geographic Coordinates of the Location $(\mathrm{m})$} \\
\hline 9 & \multicolumn{3}{|c}{ E-W Direction } \\
\hline 3 & 8 & $564,484.794$ & $4,312,796.278$ \\
1 & 2 & $563,860.376$ & $4,312,828.028$ \\
\hline 6 & 0 & $563,341.792$ & $4,312,859.778$ \\
\hline 14 & 5 & $562,706.790$ & $4,312,859.778$ \\
1 & 13 & $561,775.455$ & $4,312,912.695$ \\
12 & 0 & $560,600.703$ & $4,313,230.196$ \\
1 & 11 & $560,240.869$ & $4,313,463.029$ \\
7 & 0 & $559,563.534$ & $4,313,653.530$ \\
\hline 6 & 6 & $558,579.282$ & $4,313,695.863$ \\
\hline 10 & 5 & W-E Direction & \\
\hline 1 & 9 & $556,250.944$ & $4,313,092.612$ \\
8 & 0 & $557,256.363$ & $4,313,367.779$ \\
1 & 7 & $557,563.280$ & $4,313,357.196$ \\
5 & 0 & $558,653.366$ & $4,313,293.696$ \\
3 & 4 & $559,309.534$ & $4,313,261.946$ \\
2 & 2 & $559,859.868$ & $4,313,177.279$ \\
\hline & 1 & $560,367.869$ & $4,312,912.695$ \\
\hline & & $561,457.955$ & $4,312,574.028$ \\
\hline
\end{tabular}


Table 10. Object IDs and Counts at the 5th quadrangle.

\begin{tabular}{cccccc}
\hline Object ID & Pixel Value & Count & Object ID & Pixel Value & Count \\
\hline 1 & 0 & $1,444,159$ & 11 & 10 & 2337 \\
2 & 1 & 9470 & 12 & 11 & 1253 \\
3 & 2 & 12,220 & 13 & 12 & 824 \\
4 & 3 & 10,870 & 14 & 13 & 475 \\
5 & 4 & 12,793 & 15 & 14 & 249 \\
6 & 5 & 10,557 & 16 & 15 & 170 \\
7 & 6 & 9428 & 17 & 16 & 125 \\
8 & 7 & 6862 & 18 & 17 & 30 \\
\hline
\end{tabular}

Table 11. Locations with insufficient sight distance at the 5th quadrangle.

\begin{tabular}{cccc}
\hline Object ID & Pixel Value & Geographic Coordinates of the Location $(\mathrm{m})$ \\
\hline 3 & 2 & $553,098.683$ & \\
\hline 2 & 1 & $552,103.848$ & $4,313,800.369$ \\
1 & 0 & $552,082.681$ & $4,313,885.036$ \\
1 & 0 & $549,786.093$ & $4,313,874.453$ \\
2 & 1 & $548,558.424$ & $4,313,990.870$ \\
1 & 0 & $548,209.173$ & $4,314,012.036$ \\
2 & 1 & $547,743.506$ & $4,314,012.036$ \\
2 & 1 & $545,838.502$ & $4,314,033.203$ \\
10 & 9 & $545,108.250$ & $4,314,086.120$ \\
8 & 7 & $543,446.664$ & $4,314,075.536$ \\
\hline 1 & & W-E Direction & $4,314,160.203$ \\
\hline 1 & 0 & $544,430.916$ & \\
\hline 6 & 0 & $544,759.000$ & $4,313,736.869$ \\
1 & 5 & $545,870.252$ & $4,313,726.286$ \\
3 & 0 & $548,188.006$ & $4,313,705.119$ \\
2 & 2 & $549,299.259$ & $4,313,620.452$ \\
\hline & 1 & $550,040.094$ & $4,313,599.285$ \\
\hline
\end{tabular}

Table 12. Object IDs and Counts at the 6th quadrangle.

\begin{tabular}{cccccc}
\hline Object ID & Pixel Value & Count & Object ID & Pixel Value & Count \\
\hline 1 & 0 & $1,428,067$ & 11 & 10 & 7063 \\
2 & 1 & 7641 & 12 & 11 & 4147 \\
3 & 2 & 10,903 & 13 & 12 & 3441 \\
4 & 3 & 8864 & 14 & 13 & 2200 \\
5 & 4 & 10,727 & 15 & 14 & 2005 \\
6 & 5 & 9442 & 16 & 15 & 767 \\
7 & 6 & 9873 & 17 & 16 & 190 \\
8 & 7 & 7181 & 18 & 17 & 91 \\
\hline
\end{tabular}




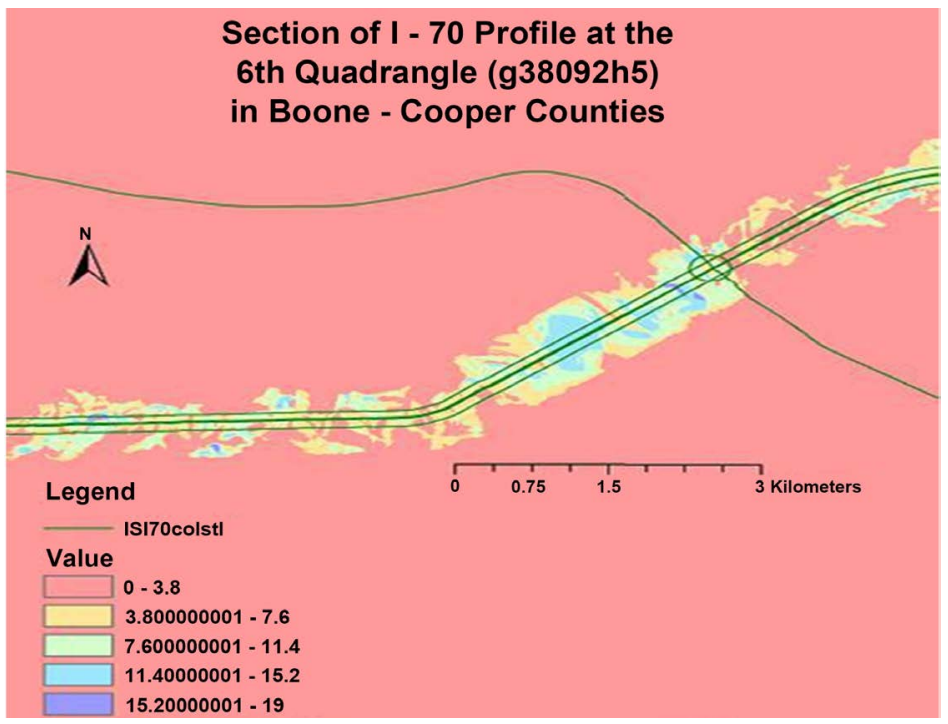

Figure 17. The I-70 classified Profileat the $6^{\text {th }}$ quadrangle in Boone-Cooper Counties.



Figure 18. The I-70 classified Profile (second image) at the $6^{\text {th }}$ quadrangle in Boone-Cooper Counties.

The locations that did not meet the AASHTO standard stopping sight distance of $220 \mathrm{~m}$ at the $6^{\text {th }}$ quadrangle, are shown in Table 13.

\section{Conclusions}

Stopping Sight Distance is a measure of the road visibility and is defined as the length of roadway ahead that is visible to the driver. This distance allows a driver to see an object in the roadway and stop their vehicle before colliding with the object. A roadway should be designed to provide continuous stopping sight distance throughout the route. Sight distance criteria have impact on virtually all elements of highway design and many elements of the traffic operation, control, 




Figure 19. The I-70 classified Profile (third image) at the $6^{\text {th }}$ quadrangle in Boone-Cooper Counties.

Table 13. Locations with insufficient sight distance at the 6th quadrangle.

\begin{tabular}{|cccc|}
\hline Object ID & Pixel Value & Geographic Coordinates of the Location $(\mathrm{m})$ \\
\hline 5 & & E-W Direction & \\
\hline 2 & 4 & $540,590.674$ & $4,313,656.531$ \\
\hline 1 & 1 & $540,299.631$ & $4,313,365.489$ \\
\hline 3 & 0 & $540,233.485$ & $4,313,325.801$ \\
\hline 2 & 2 & $539,717.547$ & $4,312,915.696$ \\
\hline 1 & 1 & $532,600.241$ & $4,310,322.774$ \\
\hline 2 & & W-E Direction & \\
\hline 3 & 0 & $532,798.679$ & $4,309,859.753$ \\
5 & 1 & $533,830.556$ & $4,309,846.524$ \\
1 & 2 & $535,920.769$ & $4,309,965.586$ \\
1 & 4 & $536,754.208$ & $4,309,965.586$ \\
1 & 0 & $539,915.985$ & $4,312,465.904$ \\
3 & 0 & $540,352.548$ & $4,312,862.780$ \\
5 & 0 & $540,431.923$ & $4,312,902.467$ \\
\hline
\end{tabular}

and their effects on traffic stream conditions. A methodology was presented in this paper to evaluate the current existing sight distances at portions of the I70 interstate highway in the State of Missouri within the Callaway, Boone, and 
Cooper counties. The method used hereby utilized the GIS capability of analyzing the visibility of a line or area through creating viewsheds for six quadrangles along the I70 alignment. A standard AASHTO stopping sight distance of $730 \mathrm{ft}$ $(220 \mathrm{~m})$ was compared to the existing sight distances, and the IDs and coordinates of the points that did not meet the AASHTO requirements were identified. The steps used to generate the viewsheds and profile maps of the I70 interstate highway were as follows:

- Importing the E00 interchange files into GIS coverage files

- Densifying the I70 raster

- Converting the Vertices of I70 Features to Points

- Adding new parameters to the attribute table of the point's raster that control the visibility analysis in the viewsheds. These parameters were (OFFSET A = $1.08 \mathrm{~m}$ presenting the height of the driver's eye recommended by AASHTO, OFFSET B $=0.6 \mathrm{~m}$ presenting the height of object above the road surface recommended by AASHTO, AZIMUTH $1=0$, AZIMUTH $2=180$ degrees, Vertical Angle $1=+90$ degrees, Vertical Angle $2=-90$ degrees, RADIUS $1=$ 0 , RADIUS $2=560 \mathrm{~m}$ presenting the radius of curvature recommended by AASHTO).

- Creating viewsheds for all points of the I70 point's raster at once

- Buffering the DEMs by a distance of $200 \mathrm{~m}$

- Clipping the DEMs by the road buffers

- Connecting the buffered-clipped DEMs of all segments together by Mosaic tools

- Generating the I70 profiles, and classified maps from the viewshed's raster's

- Identifying the IDs, and the geographic coordinates of all the points along the highway that did not meet the AASHTO recommended sight distance of $220 \mathrm{~m}$

This method can be considered as a relevant aid for assessing geometric consistency of the I70 interstate highway and/or similar roads, because it identifies adjacent segments of the road layout that offer considerably different sight distances. In addition, the stopping sight distance profile presented in this paper can also be a useful tool for understanding location-based risks of limited stopping sight distance. The profile shows the spots of insufficient stopping sight distance along the roadway, thereby illustrating the sight distance restrictions and where they occur. This information can help designers understand the severity of a sight distance restriction, how the restriction may interact with other roadway conditions or features, and how/where to implement mitigation strategies. The method presented in this paper can be further expanded to include other types of highway sight distances, such as the passing sight distances, and the decision sight distances which are classified as important highway design criteria besides the stopping sight distances presented hereby. Also, additional portions of the I70 alignment can be added for the purpose of sight distance evaluation. Crash analysis at the locations that did not meet the AASHTO sight distance requirements can be further conducted for enhancing the safety at these locations. 


\section{Conflicts of Interest}

The author declares no conflicts of interest regarding the publication of this paper.

\section{References}

[1] American Association of State Highway and Transportation Officials (AASHTO) (2011) A Policy on Geometric Design of Highways and Streets. Washington DC.

[2] Azimi, M. and Hawkins, H. (2013) Algorithm for Analyzing Horizontal Sight Distance from Lane Centerline Coordinates. Transportation Research Record: Journal of the Transportation Research Board, 2358, 12-19. https://doi.org/10.3141/2358-02

[3] Ben-Arieh, D., Chang, S., Rys, M. and Zhang, G. (2004) Geometric Modeling of Highways Using Global Positioning System Data and B-Spline Approximation. Journal of Transportation Engineering, 130, 632-636. https://doi.org/10.1061/(ASCE)0733-947X(2004)130:5(632)

[4] Cai, H. and Rasdorf, W. (2008) Modeling Road Centerlines and Predicting Lengths in 3-D Using LIDAR Point Cloud and Planimetric Road Centerline Data. Computer-Aided Civil and Infrastructure Engineering, 23, 157-173.

https://doi.org/10.1111/j.1467-8667.2008.00518.x

[5] Abdulhafedh, A. (2017) Identifying Vehicular Crash High Risk Locations along Highways via Spatial Autocorrelation Indices and Kernel Density Estimation. World Journal of Engineering and Technology, 5, 198-215. https://doi.org/10.4236/wjet.2017.52016

[6] Castro, M., Iglesias, L., Rodríguez-Solano, R. and Sánchez, J.A. (2006) Geometric Modelling of Highways Using Global Positioning System (GPS) Data and Spline Approximation. Transportation Research Part C-Emerging Technologies, 14, 233-243. https://doi.org/10.1016/j.trc.2006.06.004

[7] Fisher, P.F. (1996) Extending the Applicability of Viewsheds in Landscape Planning. Photogrammetric Engineering and Remote Sensing, 62, 1297-1302.

[8] Imran, M., Hassan, Y. and Patterson, D. (2006) GPS-GIS-Based Procedure for Tracking Vehicle Path on Horizontal Alignments. Computer-Aided Civil and Infrastructure Engineering, 21, 383-394.

https://doi.org/10.1111/j.1467-8667.2006.00444.x

[9] Khattak, A.J. and Shamayleh, H. (2005) Highway Safety Assessment through Geographic Information System-Based Data Visualization. Journal of Computing in Civil Engineering, 19, 407-411. https://doi.org/10.1061/(ASCE)0887-3801(2005)19:4(407)

[10] Kitzpatrick, K., Fambro, D.B. and Stoddard, A.M. (2000) Safety Effects of Limited Stopping Sight Distance on Crest Vertical Curves. Transportation Research Record: Journal of the Transportation Research Board, 1701, 17-24. https://doi.org/10.3141/1701-03

[11] Abdulhafedh, A. (2017) A Novel Hybrid Method for Measuring the Spatial Autocorrelation of Vehicular Crashes: Combining Moran's Index and Getis-Ord $\mathrm{G}_{\mathrm{i}}$ Statistic. Open Journal of Civil Engineering, 7, 208-221.

https://doi.org/10.4236/ojce.2017.72013

[12] Nehate, G. and Rys, M. (2006) 3D Calculation of Stopping-Sight Distance from GPS Data. Journal of Transportation Engineering, 132, 691-698. https://doi.org/10.1061/(ASCE)0733-947X(2006)132:9(691) 
[13] Polus A., Livneh, M. and Frischer B. (2000) Evaluation of the Passing Process on Two-Lane Rural Highways. Transportation Research Record: Journal of the Transportation Research Board, 1701, 53-60. https://doi.org/10.3141/1701-07

[14] Rose, E.R., Hawkins, H.G., Holick, A.J. and Bligh, R.P. (2004) Evaluation of Traffic Control Devices: First Year Activities. FHWA/TX-05-0-4701-1, Texas Transportation Institute.

[15] Berbel, D.C., Castro, M., Medina. L.C. and Maria, S.P.G. (2014) Sight Distance Studies on Roads: Influence of Digital Elevation Models and Roadside Elements. Procedia-Social and Behavioral Sciences, 160, 449-458. https://doi.org/10.1016/j.sbspro.2014.12.157

[16] Abdulhafedh, A. (2017) How to Detect and Remove Temporal Autocorrelation in Vehicular Crash Data. Journal of Transportation Technologies, 7, 133-147. https://doi.org/10.4236/jtts.2017.72010

[17] Shaker, A., Yan, W.Y. and Easa, S. (2011) Construction of Digital 3D Highway Model Using Stereo IKONOS Satellite Imagery. Geocarto International, 26, 49-67. https://doi.org/10.1080/10106049.2010.537785

[18] Tsai, Y., Hu, Z. and Wang, Z. (2010) Vision-Based Roadway Geometry Computation. Journal of Transportation Engineering, 136, 223-233.

https://doi.org/10.1061/(ASCE)TE.1943-5436.0000073 